\title{
Capítulo 28
}

\section{Conexões criativas entre pessoas e lugares: possiveis ações do designer em projetos no território}

Lia Krucken

Pensar o território como "âmbito de projeto" e compreender as dinâmicas que nele se inter-relacionam constitui um grande desafio para o design. Um território não é um projeto, nem é projetável (como projeta-se um produto). Mas o ato de projetar está sempre localizado em um território e este contexto localizado (seja fisicamente ou virtualmente) é parte do projeto. Este texto tem como propósito justamente refletir sobre possíveis contribuições do design para promover melhorias e inovações no território e com as pessoas que ali vivem, considerando os recursos e as dinâmicas que constituem um local específico.

\section{Ampliando a percepção de território}

Dos vários caminhos que esse estudo pode tomar, destaco uma vertente: as relações criativas do homem no e com o território, seu entorno. Para iniciar a reflexão tomo emprestada a palavra heimat, da língua alemã. Heimat significa casa, lar, pátria, terra. Theis (2011) aponta que cada uma destas palavras possui vários sentidos diferentes e, mesmo assim, nenhuma delas pode ser utilizada como uma tradução exata. A conotação de heimat inclui sentimentos relacionados à nostalgia e até mesmo uma dimensão de mito, como destaca Flusser (2003) ao descrever "os desafios do migrante". O autor observa que nós estamos conectados ao heimat por diversas ligações, a maior parte delas estão escondidas e não acessíveis à consciência.

É interessante analisar o uso dessa palavra por Vilém Flusser (19201991), ${ }^{1}$ cuja obra transita em diversas áreas - da filosofia ao design. De origem tcheca, Flusser mudou-se para o Brasil fugindo do nazismo, em 1940.

1 Para saber mais sobre a obra de Vilém Flusser: http://www.flusserbrasil.com/biografia.html 
Naturalizado brasileiro, Flusser atuou por cerca de 20 anos como professor de filosofia, jornalista, conferencista e escritor. Em 1967, torna-se professor de filosofia da ciência na Universidade de São Paulo e, em 1972, assina a coluna diária "Ponto Zero" no jornal Folha de São Paulo. Artigos dessa época foram organizados em vários livros, que têm sido traduzidos em diversas línguas, e sua obra continua atual e impactante.

Recentemente, em 2016, a Academia de Arte de Berlim organizou uma mostra sobre o seu trabalho, intitulada "Without Firm Ground", ${ }^{2}$ na qual seus textos e pensamento são descritos como "um contínuo experimento de viver e sobreviver na diáspora”. A obra que abre a exposição é um grande painel de deslocamentos e agrupamentos feitos pelo Flusser, seja em termos de áreas de conhecimento, seja geograficamente. A questão do território (no sentido amplo da palavra) aparece de novo como elemento central no trabalho de Flusser, que afirma que "o misterioso sentimento de heimat liga-se a pessoas e coisas" (2003, p. 5).

Pareceu-me oportuno citar o seu trabalho neste texto. Como um importante pensador do design, Flusser foi capaz de dialogar com diversas culturas e territórios, incluindo o Brasil como lugar que permitiu o pensamento. ${ }^{3}$ Particularmente sobre as relações entre "Território e Design”, a abordagem que o autor traz sobre heimat pode ser interessante para ampliar uma reflexão crítica, evidenciando a dimensão humana. Além disso, a própria trajetória de Flusser reflete uma condição cada vez mais comum, que é a de atuar em contextos multiculturais e abordar questões socioculturais complexas.

Não é o propósito desse texto analisar conotações político-econômicas relacionadas à palavra território. O que se quer destacar nessa reflexão é justamente a escala humana e a dimensão afetiva do território. Mas para isso é necessário contextualizar a discussão e entender como as palavras são usadas. Território é um termo complexo, porque abarca diversas escalas e perspectivas.

2 http://www.adk.de/de/programm/?we_objectID=49530

3 Ainda que Flusser tivesse várias críticas, é notadamente no Brasil que encontrou lugar para desenvolver sua carreira: "[Brasil] é ao mesmo tempo estimulante e frustrante para alguém interessado no estudo e na investigação da filosofia. É estimulante porque praticamente tudo o que se faz é um trabalho pioneiro... é frustrante porque os grupos intelectuais "oficiais"... são rigidamente divididos em dois campos rivais, o marxista e o católico.” - trecho da carta que Flusser escreveu a Lionel Ruby em 1962, da Associação Filosófica Americana, destacado por Finger (2003). A essa carta, na qual Flusser indicava interesse em atuar em uma "atmosfera de universidade mais independente" nos Estados Unidos, recebe a resposta "Seria extremamente difícil [para você] obter uma posição como professor sem uma titulação". Paradoxalmente, atuando como professor da Universidade de São Paulo, em 1967 Flusser viaja por seis meses representando o Brasil, a convite do Itamaraty, em uma série de conferências sobre a filosofia brasileira nos Estados Unidos e na Europa. 
Como aponta Storey (2013), vivemos em um mundo altamente territorializado e a manifestação mais óbvia deste fato é a divisão política da terra em países ou estados separados. Seguindo a lógica proposta pelo autor, território pode ser definido como um "espaço delimitado" (pelas fronteiras) e o processo pelo qual grupos e indivíduos reivindicam um território pode ser descrito como territorialidade. A ambiguidade da palavra fica clara quando se pergunta: por que ou para quem a territorialidade se estabelece? Territorialidade é uma estratégia geográfica poderosa para controlar pessoas e coisas, por meio do controle de uma área, destaca Sack (1986). O autor defende a ideia de que territorialidade se tornou, na modernidade, instrumento político-estratégico para alocar/deslocar significado ao espaço, de tornar impessoais as relações sociais e de obscurecer as fontes de poder (ibid, p.2). Essas considerações foram selecionadas com o objetivo de esclarecer que ao se falar aqui, nesse texto, sobre território, buscam-se alternativas à visão controladora e limitadora que pode estar embutida no conceito de território.

O geógrafo Milton Santos (1926-2001) desenvolveu uma longa obra focalizada no conceito de território, espaço e lugar e nas dinâmicas entre territórios. O autor observa que "o território não é um dado neutro nem um ator passivo" e inclui a dimensão temporal ao afirmar que "o espaço geográfico não apenas revela o transcurso da história como indica a seus atores o modo de nela intervir de maneira consciente" (SANTOS, 2000, p. 96). Citando a definição proposta pelo autor: "O território é o chão e mais a população, isto é, uma identidade, o fato e o sentimento de pertencer àquilo que nos pertence. $\mathrm{O}$ território é a base do trabalho, da residência, das trocas materiais e espirituais e da vida, sobre os quais ele influi" (ibid).

Essa abordagem de "território vivido" remete ao conceito de 'terroir', original do francês, empregado para definir um território caracterizado pela interação com o homem ao longo dos anos, cujos recursos e produtos são fortemente determinados pelas condições do solo, do clima e culturais. De acordo com o French National Institute for Agricultural Research (INRA, 2002, tradução livre), o terroir pode ser considerado como "uma entidade territorial cujos valores patrimoniais resultam de relações complexas entre elementos culturais, sociais, ecológicos e econômicos, que se desenvolveram ao longo do tempo". Desta forma, citando Barjolle et al. (1998, p. 10, tradução livre), um terroir compreende um espaço geográfico complexo, caracterizado por três perspectivas: um território com suas condições edafoclimáticas; um ambiente de conhecimentos e práticas; um conjunto de tradições e costumes localizados. Esse tema foi investigado também em trabalhos anteriores por Krucken $(2008 ; 2009)$.

Alguns autores apontam o ressurgimento da valorização do local e do pertencimento cultural - como terroir na França, heimat na Alemanha (ainda que estas palavras tenham sentidos bastante diversos) - na década de 1970. Esses 
sentimentos seriam uma resposta à "experiência de desterritorialização, deslocamento e alienação que aumentavam com a globalização" (GOODBODY, 2011).

É interessante notar que esses movimentos de repensar "o local" e o "território de origem" também se encontram com a crescente preocupação com o meio ambiente. "Conexões emocionais com um lugar nos fazem mais sensíveis às mudanças ambientais e mais desejosos de tomar ações para protegê-lo" ressalta Goodbody (2011), ao relacionar Heimat ao movimento ambientalista na Alemanha. Sobre esse aspecto é importante destacar que Heimat é uma unidade espacial não formal, não legalística (que não indica propriedade e que não pode ser possuído), que abarca simultaneamente várias dimensões: “o lugar, a cidade natal, a região e o país" (ibid, p.18). Talvez por esse caráter multidimensional, ${ }^{4} \mathrm{o}$ sentido de heimat associado à sustentabilidade encontra ressonância em movimentos participativos e democráticos "bottom-up". Outro aspecto interessante é a necessidade de redefinição da conexão ao heimat em um mundo que se torna crescentemente "diásporo e transacional” (GOODBODY, 2011), por meio das dinâmicas de migração, por exemplo.

Ao meu ver, a questão mais interessante que essas palavras trazem é a ideia de pertencimento, especialmente em relação à dimensão simbólica, que é tão necessária para que as pessoas se sintam parte de uma sociedade e possam desenvolver ações/ projetos democráticos (e também cuidar do lugar, reconhecer direitos e deveres em relação ao espaço coletivo). E pensando como designer: o que significa considerar o território como âmbito do projeto de design? Como incorporar também a noção de casa, lugar, paisagem, e ir além das fronteiras objetivas da palavra território?

\section{Território afetivo e lugar do projeto}

"Colocar em perspectiva o território é, necessariamente, uma opção pelo local, seja qual for a dimensão que essa instância possa ter”, afirma Leite (2015, p. 34). Fazer um recorte de base territorial "nos coloca em contato com demandas mais imediatas da população e também com as potencialidades que emergem das comunidades" continua o autor (ibid). Leite (2015) também observa que atuar no nível local nos permite criar soluções para problemas globais, tendo a "qualidade de vida como centro articulador das experiências na busca do bem viver e do bem comum".

Essas considerações se aproximam da noção de "localismo cosmopolita", proposta por Wolfgang Sachs no seu livro Dicionário do desenvolvimento, publicado originalmente em 1992. A busca por "unidades centradas no espaço" está evoluindo para a busca de "diversidades centradas no lugar", aponta Sachs

4 Como destaca Morin (p.177): o planeta é “nossa casa, home, heimat, é nossa mátria e, mais ainda, nossa Terra-Pátria". O autor considera o "futuro comum" do planeta como base para o manifesto "From Homeland Earth; A New Manifesto For The New Millennium". 
(1992, p. 122). Isso significa, por exemplo, reavivar o interesse por línguas locais e redescobrir sistemas tradicionais de conhecimento, bem como pensar alternativas para uma revitalização econômica local. Assim, o autor ressalta a importância da diversidade, tanto na cultura como na natureza, e seu potencial de inovação e de fomento para soluções criativas, não lineares.

Com base nessa definição de Sachs, Manzini (2012) acrescenta que o "localismo cosmopolita" produz um novo modelo de bem-estar: "um bem-estar no qual se reconhece o quanto os contextos socioculturais e ambientais podem contribuir para a qualidade de vida das pessoas e para a resiliência de toda a sociedade". Contextos podem ser entendidos como tecidos sociais vivos, uma paisagem ou a riqueza de diversidades que um lugar pode expressa, continua o autor.

Nesse sentido, a cultura e a arte, assim como o design, têm papel fundamental no desenvolvimento de um imaginário, de visões de mundo possíveis, nos quais essas diversidades podem se manifestar, e que antecedem a ação e o projeto nos diversos contextos. Silva (2006, p. 57) destaca que a percepção mental e física de um território se apoia em operações linguísticas e visuais. O território "se nomeia, se mostra ou se materializa em imagens, em jogos de operações simbólicas, que por sua própria natureza produz seus conteúdos e marcas seus limites”, afirma o autor. Silva (2006, p. 106) destaca ainda a relação entre o imaginário e a forma de narrar o território (especialmente o contexto urbano): "o imaginário afeta, filtra e modela a nossa percepção de vida e tem grande impacto na elaboração dos relatos sobre a cotidianidade". É nessa dimensão simbólica, cultural, que os imaginários urbanos expressam sua potência estética e política e que passamos de uma "cidade de edifícios" para um "urbanismo dos cidadãos" (SILVA, 2006, p. 55).

Ter como foco de projeto o território pode significar, portanto, desenvolver ou apoiar projetos que vão desde construções mentais e imaginários, até o desenvolvimento de soluções "concretas", relacionadas às demandas existentes ou latentes. Assim, identifico algumas questões para reflexão:

- Como as competências do designer podem contribuir para promover a qualidade de vida em um território (espaço público, bairro, cidade)?

- Como as ferramentas de Design podem apoiar cidadãos e comunidades a compreender o território e a desenvolver soluções/estratégias que permitam o uso de seus recursos de forma sustentável?

- Como dar visibilidade a dinâmicas, histórias e características de um território? Essas questões não esgotam a reflexão, pelo contrário, abrem-na mais ainda. A análise de algumas iniciativas pode nos ajudar a identificar possíveis ações do designer tendo como âmbito de projeto um território. São apresentados três casos no Brasil: os dois primeiros referem-se a criação de imaginários urbanos, o último refere-se ao desenvolvimento de estratégias para fortalecer a capacidade criativa do território. 


\section{Coletivo Coletores - projeto Media Lab São Mateus em Movimento}

O COLETORES tem como proposta pensar a cidade como meio e suporte para suas ações a partir de conceitos como: arte e jogo, arquitetura do precário, design social, arte interativa e arte digital. É um Coletivo de arte/intervenção urbana, formado em 2008 na cidade de São Paulo pelos artistas Toni William Crosss e Flávio Camargo. O projeto Media Lab São Mateus em Movimento ${ }^{5}$ contou com o apoio do edital Redes e Ruas da cidade de São Paulo e envolveu uma série de intervenções digitais e ações culturais realizadas em 2015. Os autores definem o projeto como um processo de pesquisa-ação em que "enquanto você trabalha, você também observa" (MARINO, 2015, p. 7). Como forma de (re)significar as lutas e resistências no território (nesse caso, a favela de Vila Flávia e a região de São Mateus), os coletivos se apropriaram do universo da cultura digital e o trabalho envolveu a noção de "direito à cidade". Segundo os idealizadores do projeto, que se baseiam na noção proposta por Harvey (2012), o direito à cidade não é o direito a algo que já está definido, mas, pelo contrário, caracteriza-se como o direito de reconstruir, recriar uma cidade diferente. Inicialmente pensadas como projeções na região de São Mateus (Figura 1), as imagens criadas pelo coletivo passaram a ser projetadas no centro da cidade de São Paulo, atingindo outros públicos na proposta de refletir criticamente sobre o espaço urbano.
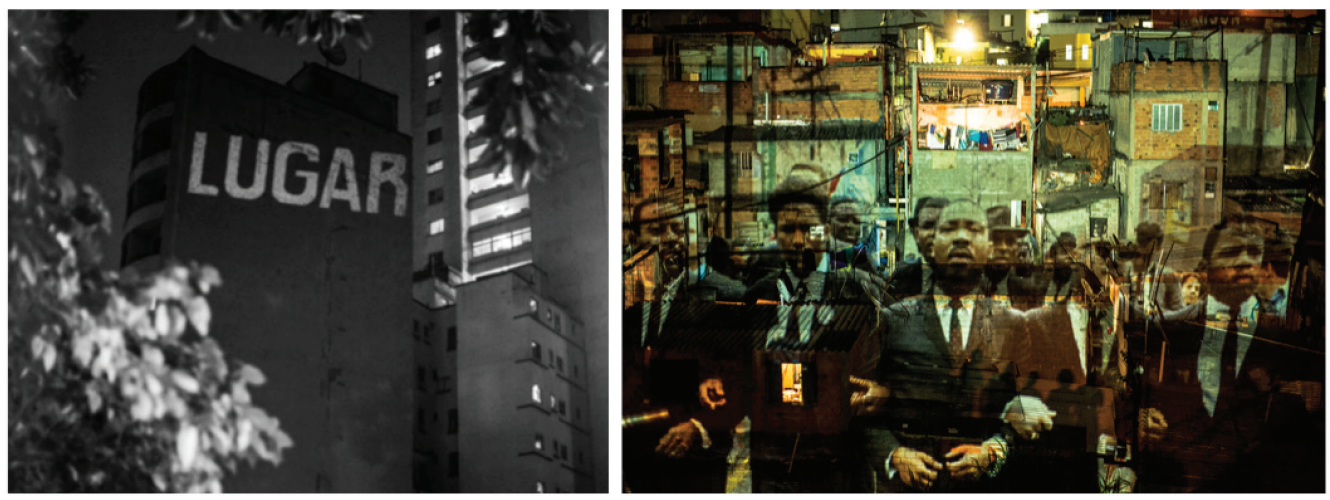

Figura 1 Projeções desenvolvidas pelo coletivo Coletores, que provocam uma reflexão sobre o espaço urbano. Fonte: Coletivo Coletores - Marino et al. (2015).

Esse projeto mostra um interessante uso da tecnologia para promoção da participação social, possibilitando explorar diferentes espaços da cidade, com diferentes linguagens poéticas. Ao dar visibilidade a elementos históricos presentes nas narrati-

5 Para saber mais, assista ao vídeo do projeto em: https://www.youtube.com/watch?$\mathrm{v}=6 \mathrm{BS} 7 \mathrm{rZW} 6 \mathrm{~T} 6 \mathrm{E}$. 
vas sobre o lugar, bem como a manifestações como a dança de rua e grafite, o projeto propõe experimentações estéticas e apropriação afetiva do território. As ferramentas tecnológicas, conforme destaca Bellix (2015) ao avaliar os resultados do projeto, constituem "elementos transversais que estão a serviço da cidadania" e seu uso pode provocar mudanças culturais no sentido de democratizar o uso do espaço público.

\section{Espírito do lugar e geografia imaterial - oficinas colaborativas em Belo Horizonte}

Essa iniciativa se desenvolveu a partir de uma série de oficinas abertas à comunidade durante 2013 e 2014, com o objetivo de entender o espírito do lugar e promover um debate democrático sobre a qualidade de vida no território. Cada oficina aborda um tema específico, escolhido em conjunto com os participantes - cidadãos, designers e artistas. As atividades incluíram explorações fotográficas na cidade e desenvolvimento de imagens e visões relacionadas ao desejos e aspirações para o espaço público. Em 2014, por exemplo, o tema trabalhado foi a água, tendo como foco contribuir para a conscientização dos valores culturais e sociais relacionados a esse recurso ambiental. ${ }^{6} \mathrm{O}$ ponto de partida foi identificar rios e canais que passavam pelo centro da cidade de Belo Horizonte que se encontram cobertos por concreto.

Os métodos (Figura 2) incluíram o desenvolvimento de mapas coletivos, análise iconográfica e de conteúdo e a curadoria coletiva de uma exposição aberta ao público no Centro Cultural da UFMG de abril a agosto de 2014.

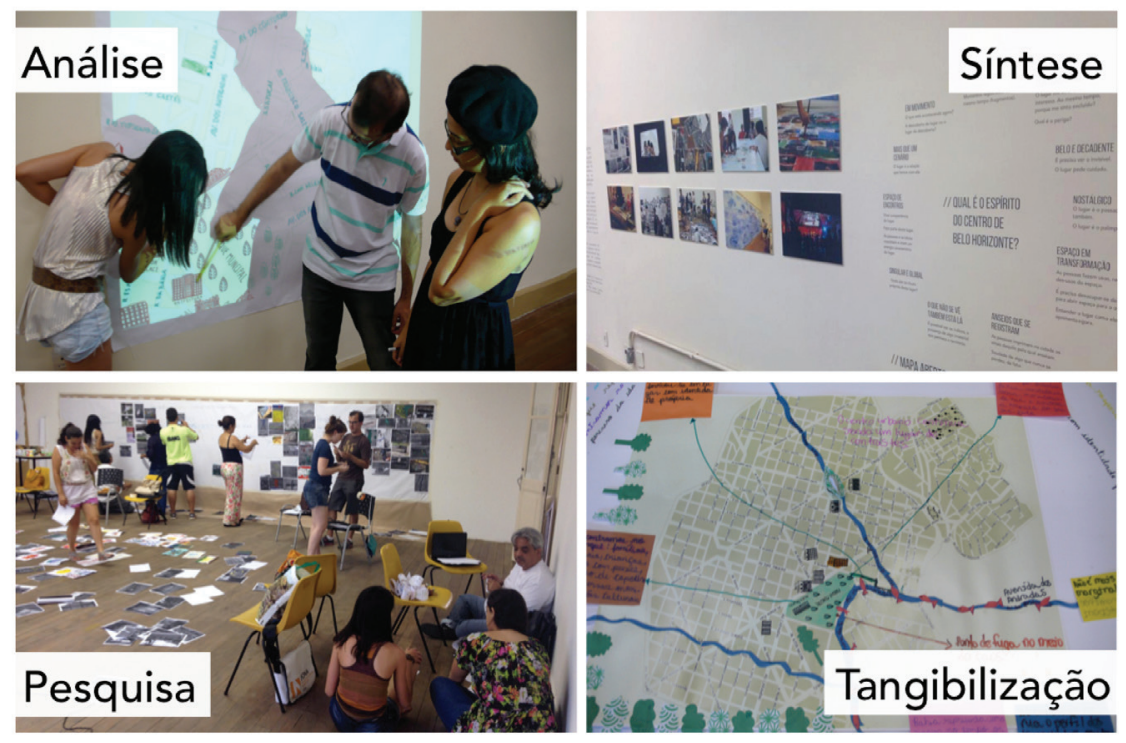

Figura 2 Panorama geral do processo de design.

Fonte: autora, 2014.

6 Para saber mais, assista à entrevista sobre a oficina em: https://youtu.be/yNFbAy-tpt4. 
Esse projeto dá visibilidade aos desejos e aspirações de moradores locais (visões de um futuro desejável), associados às narrativas sobre o lugar. A exposição dos resultados foi aberta ao público, que foi convidado a interagir na análise realizada.

\section{Studio Superfluo - laboratórios de cocriação com a comunidade}

Como pensar um território em função dos resíduos nele gerados e que podem, por sua vez, gerar novas riquezas? Esse é um dos desafios que o Studio Superfluo se coloca em seus projetos com comunidades, baseados em princípios de design sistêmico (BISTAGNINO, 2010). Dentre os projetos realizados destaca-se o Laboratório Criativo realizado em 2014 com a Associação de catadores Ascapéu, na cidade de Pompéu, em Minas Gerais (Figura 3). ${ }^{7}$ Essa iniciativa envolveu a sensibilização sobre as potencialidades de reusar materiais, o mapeamento de resíduos gerados na cidade e dos atores que poderiam ser envolvidos na solução de design, levantamento de fundos (realizado por meio da plataforma de crowdfunding Catarse) e o experimento de um modelo de produção artesanal sustentável no território - que inclui a criação de novos postos de trabalho para os catadores, formação sobre temas relacionados a sustentabilidade, capacitação para a realização de projetos e desenvolvimentos de novos produtos. Sob esse aspecto, é importante citar que um dos produtos gerados nesse projeto foi selecionado para o prêmio nacional "Objeto Brasileiro" em 2014.
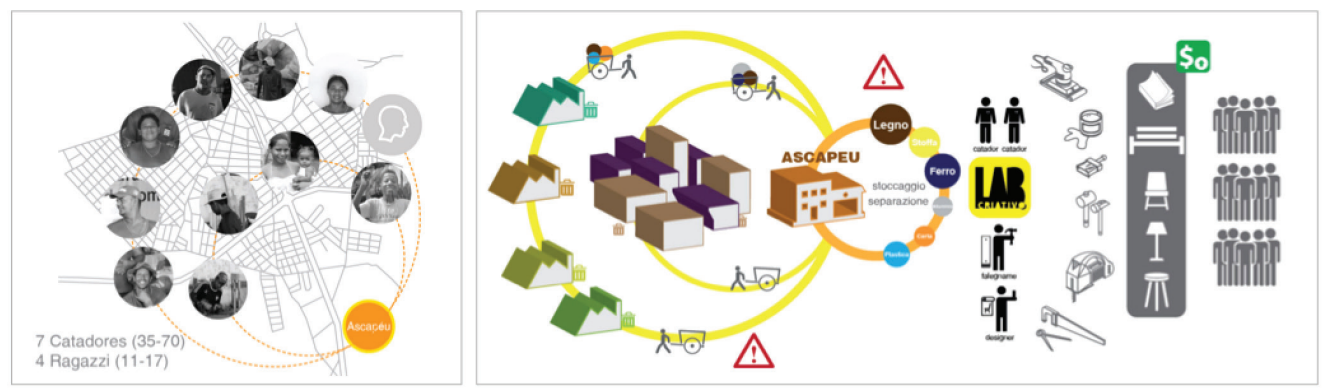

Figura 3 Ciclo virtuoso de resíduos urbanos para a cidade de Pompéu envolvendo atores no território.

Essa iniciativa se baseia na percepção do território como um ecossistema e na intervenção do Design para desenvolver ciclos virtuosos que gerem maior qualidade de vida e sustentabilidade. Como afirmam os coordenadores do projeto, o trabalho desenvolvido cria oportunidades de compartilhamento a serviço da cidade - por exemplo o uso coletivo das ferramentas do Laboratório Criativo, adquiridas a partir do crowdfounding.

7 http://studiosuperfluo.com/portfolio/lab-criativo-·-pompeu/. 


\section{Possíveis contribuições do designer}

As iniciativas discutidas possibilitam observar diversos aspectos, especialmente relacionados: a) à percepção do território e estímulo ao desenvolvimento de visões de "futuros desejáveis"; b) à interação entre atores em ações e soluções coletivas; c) ao uso de ferramentas de design para apoiar processos relacionados a mapeamento, visualização, comunicação, pesquisa e projeto, dentre outros.

Sobre a interação entre atores no desenvolvimento de ações e soluções coletivas, é interessante pensar o papel das organizações colaborativas como "place makers", como indica Manzini (2015, p. 194).

Dentre as organizações colaborativas podemos destacar os coletivos culturais, que vêm se consolidando como um movimento social presente em muitas cidades latino-americanas na última década. Esses coletivos podem provocar novas dinâmicas no território, assim como gerar novas formas de entender o tecido social, em termos de conexões e valores. Em muitos casos, esses coletivos relacionam-se com ações de resistência, seja em defesa dos direitos dos cidadãos e de qualidade de vida coletiva, ou de alternativas mais sustentáveis (ambiental, econômica, cultural e social) no uso do território e espaços do cotidiano.

Nesse sentido, estas organizações podem contribuir para a criação de lugares mais habitáveis e para melhorar a "ecologia territorial": "Se um território é um ecossistema de lugares e comunidades, a construção ou reconstrução desses lugares e comunidades, considerando toda sua variedade e riqueza cultural, também conduz ao desenvolvimento de um ecossistema mais rico e variado e, portanto, mais resiliente" (ibid).

Os mecanismos para desenvolver lugares mais resilientes estão emergindo na prática, como vários casos demonstram. Estruturas fundamentais incluem, conforme apontam Brown e Harris (2015): uma linguagem inclusiva (por exemplo, adotando "e" em vez de "mas", e "ambos" em vez de "ou"), um repensar sobre ciência, uma democracia direta, a gestão recíproca de recursos, um aprendizado intenso e uma identidade coletiva.

Ao abordar questões amplas como estas, evidencia-se a importância da integração de linguagens e conhecimentos de várias áreas. É neste contexto dinâmico que algumas características próprias da disciplina de Design, como a riqueza interpretativa e a habilidade visionária - ou antecipatória, como aponta Maldonado (1976) -, podem contribuir para o desenvolvimento de uma pluralidade de soluções e de cenários de futuro (KRUCKEN, 2008). Como reforça Margolin (2000): "Design é, também, uma atividade integrativa que, em um sentido amplo, combina conhecimento de múltiplos campos e disciplinas para obter resultados específicos. Possui, simultaneamente, uma dimensão semântica e uma dimensão técnica e operativa”. 
Várias outras iniciativas relacionadas à transformação do território por meio de projetos coletivos podem ser apontadas. A título de exemplo, destacam-se alguns projetos que foram desenvolvidos com o suporte de Escolas de Design:

a) "Amplifying Creative Communities" - realizado na Parsons the New School com financiamento da Rockefeller Foundation em 2009. A percepção de que "boas ideias podem ser amplificadas" (PENIN, 2014) foi a base para este projeto, que envolveu a aplicação de ferramentas de design para aprimorar e multiplicar as soluções desenvolvidas pelas comunidades na cidade de Nova Iorque;

b) "Design for the living world" - envolve alunos da Hochschule für Bildende Künste de Hamburgo, na Alemanha, que realizam iniciativas em diversos territórios. O projeto Soweto (POTRC, 2014), na África, é uma dessas iniciativas e foi desenvolvido em 2014, tendo como foco promover o uso coletivo de um espaço público abandonado, por meio de processos colaborativos com a comunidade;

c) “A praça que queremos" - projeto realizado em 2012 junto a PUC - Rio, tendo como contexto de atuação o Complexo de favelas da Maré, uma favela de Rio de Janeiro. Foram aplicados métodos de criação participativos para renovar uma praça pública, local que se encontrava em condição de degrado junto com a população. O objetivo de projeto foi empoderar os moradores do lugar através do processo de Design e promover atitudes democráticas (GAUDIO; OLIVEIRA; FRANZATO, 2014).

As iniciativas e os projetos citados possibilitam identificar diversas contribuições do designer, tendo como foco de projeto o território. Primeiramente, ao considerar o contexto, as necessidades e os potenciais usuários, o Design pode contribuir para o entendimento de possibilidades de projeto. Ao promover o uso criativo do espaço público, por exemplo, pode-se promover uma melhoria da "relação com" o lugar e fortalecer o sentido de pertencimento, por meio da valorização de tradições, rituais e manifestações locais. No seu papel de facilitador criativo, o designer pode apoiar o desenvolvimento de soluções junto com as comunidades, valorizando o 'potencial estético e político do lugar', bem como envolver stakeholders, criando 'espaços de convergência'. Por fim, especialmente interessante é o trabalho de resgatar e dar visibilidade à memória e à identidade do lugar. Esta abordagem do 'território no tempo' é crucial para se pensar 'projetos portadores de sentido' para o presente e para o futuro.

Essa lista é aberta e segue evoluindo. Ao meu ver, vamos compreendendo e atualizando as possíveis contribuições por meio da prática e da reflexão sobre a prática. Neste sentido, é interessante observar o importante papel que as Escolas de Design podem assumir ao proporcionar 'espaços abertos de experimentação', 
que possibilitem o aprendizado pela experiência e o desenvolvimento de competências para a atuação em âmbitos complexos como são os territórios.

\section{Referências}

BARJOLLE, D. et al. Le lien au terroir. Bilan des travaux de recherche. Office fédéral de l'Agriculture et l'Institut d'Economie rurale. Lausanne, 1998. Disponível em: <https://www.aop-igp.ch/_upl/files/Lien_au_terroir.pdf>. Acesso em: 1 ago. 2010.

BELLIX, L. Tecnologia e participação: horizontes ao governo aberto. In MARINO, A.; CAMARGO, F.; SANTOS, T. Insurgências: arte, tecnologia e território. São Paulo: Centro Cultural São Mateus em Movimento, 2015. p. 68-71.

BISTAGNINO, L. Innovare: in che modo? In GERMAK, C. (Ed.). Uomo al centro del progetto. Torino: Allemandi \& C., 2008. p. 32-39.

BROWN, V. A.; HARRIS, J. A. A collective mind for a just and sustainable future. In FUAD-LUKE, A.; HIRSCHER, A.-L.; MOEBUS, K. (Org.). Agents of Alternatives: redesign our realities. Berlin: Agents of Alternatives, 2015. p. 46-57.

FINGER, A. Introduction. In FLUSSER, V. The freedom of the migrant: objections to nationalism. Bristol: University of Illinois Press, 2003. p. IX-XXII.

FLUSSER, V. The freedom of the migrant: objections to nationalism. Bristol: University of Illinois Press, 2003.

FRENCH NATIONAL INSTITUTE FOR AGRICULTURAL RESEARCH - INRA. INRA faced with Sustainable Development: Landmarks for the Johannesburg Conference. Dossiers de l'Environnement de l'INRA n 22, Paris. 213 p.

GAUDIO, C.; OLIVEIRA, A. J.; FRANZATO, C.; O tempo no design participativo. In Anais do $11^{\circ}$ Congresso Brasileiro de Pesquisa e Desenvolvimento em Design. São Paulo: Blucher, 2014. p. 957-969.

GOODBODY, A. Heimat's environmental turn. In ASLE Conference “Species, Space, and the Imagination of the Global”, Boomington, 2011.

HARVEY, D. Rebel cities: From the right to the city to the urban revolution. London, New York: Verso, 2012. 
KRUCKEN, L. Skills for design in contemporary society. In MORAES, D.; KRUCKEN, L. (Ed.). Design and transversality. Belo Horizonte: Santa Clara, 2008.

. Design e território: valorização de identidades e produtos locais. São Paulo: Nobel, 2009.

LEITE, A. E. Território: espaços afetivos. In MARINO, A.; CAMARGO, F.; SANTOS, T. Insurgências: arte, tecnologia e território. São Paulo: Centro Cultural São Mateus em Movimento, 2015.

MALDONADO, T. Disegno Industriale: un riesame. Milano: G. Feltrinelli, 1999.

MANZINI, E. Design, when everybody designs: an introduction to design for social innovation. London: MIT Press, 2015.

Resilient Systems and Cosmopolitan Localism - The Emerging Scenarios of the Small, Local, Open and Connected Space. CNS Ecologia Politica, 2012.

MARGOLIN, V. Building a design research community. In PIZZOCARO, S.; ARRUDA, A.; MORAES, D. (Org.). Design Plus Research: Proceedings, 18-20 maio. Milan: Politecnico di Milano, 2000.

MARINO, A.; CROSS, T. W. Arte, tecnologia e direito à cidade. In MARINO, A.; CAMARGO, F.; SANTOS, T. Insurgências: arte, tecnologia e território. São Paulo: Centro Cultural São Mateus em Movimento, 2015.

PENIN, L. Amplifying innovative sustainable urban behaviors. Defining a designled approach to social innovation. In CROCKER, R.; LEHMANN, S. (Ed.). Behaviour Change, Consumption and Sustainable Design. Series Sustainable Design. London: Earthscan/Routledge, 2013.

POTRC, M. The Soweto Project (Design for the Living World). Berlin: Archive Books, 2014.

SACHS, W. (Ed.). The Development Dictionary: A Guide to Knowledge as Power. London: Zed Books, 1992.

SACK, R. D. Human Territoriality: Its Theory and History. Cambridge: Cambridge University Press, 1986. 
SANTOS, M. Por uma outra globalização: do pensamento único à consciência universal. São Paulo: Record, 2000.

SILVA, A. Imaginarios urbanos: cultura y comunicación urbana. Bogotá: Arango, 2006.

STOREY, D. Territory and territoriality. In WARF, B. (Ed.). Oxford Bibliographies in Geography. New York: Oxford University Press, 2013.

THEIS, W. Heimat - um termo abstrato. Revista Primus Vitam, São Paulo, v. 4, p. 1-7, 2012. 
